\title{
Nurses' Personal Values, Value Implementation at Work and the Difference Between Them
}

\author{
Salam Asaad Hadid ${ }^{1,2}$, Limor Malul ${ }^{1} \&$ Mohammad Khatib ${ }^{1}$ \\ ${ }^{1}$ Nursing Department, Zefat Academic College, Israel \\ ${ }^{2}$ Galilee Medical Center, Israel \\ Correspondence: Salam Asaad Hadid, Nursing Department, Zefat Academic College, Israel.
}

Received: December 6, 2018

Accepted: February 15, 2019

Online Published: February 20, 2019

doi:10.20849/ijsn.v4i1.545

URL: https://doi.org/10.20849/ijsn.v4i1.545

\begin{abstract}
Background: Schwarz (1992) held that all people have personal values systems which guide them. However, the degree to which nursing staff can implement personal values in the workplace can vary depending on environment and institutional policy. This study examined the personal values of nursing staff and the gap between values and their implementation at work. Method: This was a quantitative descriptive study, using demographic information and a structured questionnaire, Schwartz's Shorter Value Survey (SSVS), for examining the degree of implementation of personal values in clinical practice. Results: 425 respondents from different faiths assigned higher importance to certain values than to others, with demographic factors influencing decisions. Conclusion and Implications: Knowledge of the dominant personal values held by nursing staff may contribute to the organization's ability to cultivate and maintain the human resources within it. Institutions should be aware of possible gaps between the importance of values and the degree of their implementation.
\end{abstract}

Keywords: personal values, values implemintation, nursing

\section{Introduction}

Nurses, like others in the caring professions, bring personal sets of values to their work. Schwartz's (1992) theory of values is based on the assumption that higher-order values underlie human thinking and behavior as well as choice of profession. He assumes that behavior is motivated by personal value systems, and recognizes that they may differ from person to person (Bardi \& Schwarz, 2003). Schwartz identifies ten basic personal values that are recognized across cultures and explains how they arise. (1992).

While a high correlation between personal values and workplace values leads to higher staff satisfaction (Dolan, 2011), inability to implement personal values in the workplace may produce negative outcomes such as dissatisfaction and burnout, or even the abandonment of the profession (Maben, Latter \& Clark, 2007). The present study examined the extent to which nurses' values are influenced by demographic, academic and professional variables; the extent to which nurses can apply these values in various work areas and the gap between personal values and the ability to implement them in the field.

Schwartz's theory of cultural values

Schwartz (2012) identifies ten motivationally distinct types of values and specifies the dynamic relations among them, since some values conflict with one another and others are compatible. He defines the following ten values. Self-direction-the desire for independence in thought and behavior, curiosity, openness to change and creativity; stimulation-the desire to experience constant change, excitement and challenges; hedonism-the desire for pleasure and gratification of the senses; achievement-ambition and the desire to excel, the will to gain general recognition through one's skills; power-the desire for higher status and prestige, to be in a position of authority and to control resources; security-the desire for safety, to have stability of society, and self; conformity-the desire to abide by social norms or expectations; tradition-the desire to maintain status, to keep to the known and to avoid that which is different; benevolence-the concern for the welfare of people with whom one has daily contact; universalism-understanding, appreciation and tolerance and concern for the welfare of all people (Schwartz, 2012).

Schwarz explains the relations between the values and presents them in a circular structure to show that a given value may conflict with another or may complement another (1992). While nurses have individual value systems, 
in some work situations they may experience constraints which limit their ability to operate according to their values (Maben, Latter \& Clark, 2007). The absence of such constraints leads to greater staff satisfaction and higher subjective well-being, reduced burnout and better therapeutic outcomes for the patient (Sagiv \& Schwartz 2000; Maben, Latter and Clark 2007).

This study examined the personal values of nursing staff and the degree to which they were able to implement them in clinical practice in the workplace. Secondly, we examined the factors influencing the extent of the gap between personal values and actual workplace value implementation. We also looked at the effect of demographic variables on values and their implementation.

\section{Method}

This was a quantitative descriptive study, using data collected from respondents-nursing staff members-through a structured questionnaire. The data were collected in 2015-2016 by third year nursing students as an assignment in one of their courses at an academic college in northern Israel. Respondent consent was obtained after the study purpose was explained, and the questionnaire was filled out independently. Helsinki considerations were met by the study being approved by the ethics committee of the college.

\subsection{Respondents}

There were 425 respondents: $289(70.1 \%)$ were women and $127(29.9 \%)$ men, with mean age 39.2 years $(S D=$ 10.25). Most of them were married (78.6\%). Respondents were of different faiths; 191 (44.9\%) were Jewish, 127 (29.9\%) Muslim, 67 (15.80\%) Christian, 35 (8.20\%) Druze and the rest did not register religious affiliation. 363 $(85.40 \%)$ were regular nursing staff and the rest were in various management positions. Experience in the profession in general averaged 14.80 years $(\mathrm{SD}=10.50)$ and professional experience in the current workplace averaged 10.90 years $(\mathrm{SD}=9.20)$. About half of the participants were academic nursing staff holding a B.A. 237 $(50.80 \%), 97(22.80 \%)$ were registered nurses, $(\mathrm{RN})$, and the rest had an M.A. About half 194 (45.6\%) had done an advanced course of some kind.

Research tool: A questionnaire consisting of three parts.

Part 1. The Shorter Schwartz's Value Survey (SSVS) (2003), based on the full-length Schwartz Value Survey, examines the top ten personal and cultural values which are used as guiding principles in people's lives. Schwartz (1997) used 56 items used to measure the 10-value taxonomy. A Shorter 21-item version was later developed for the European Social Survey (ESS), each value typically based on two items (Schwartz, 2003). In this study, the SSVS was tested for validity and reliability for all ten values; Cronbach's $\alpha$ ranged from.65 to.88. Participants were asked to indicate the degree of importance of each of 21 statements on a scale of 1-6, where 1 $=$ not at all important to me and = very important to me. The ten values were calculated by averaging the answers received for questions that tested the same value.

Part 2 was a questionnaire on the extent to which implementation of personal values in clinical practice was possible. Subjects were asked to rate statements on a scale of 1-6 scale, where $1=$ strongly disagree, $6=$ strongly agree. The questionnaire was reliable (Cronbach's $\alpha=.93$ ). The degree of application of each value was calculated as the average of responses to each question. Part 3 was a demographic information questionnaire, which included questions about age, gender, religious affiliation, marital status, work role, academic degree, and professional seniority. Data included a description of the study population and distributions, averages and standard deviations were calculated. Statistical tests of correlation and analysis of variance were performed as required using SPSS.

\section{Results}

The first analysis was of degree of value importance, ability to implement, and the gap between them.

Table 1 about here 
Table 1. Means and standard deviations for the degree of importance of ten values for respondents, the possibility of their implementation in the workplace and the mean difference between them, on a scale of $1-6, n$ $=425$

\begin{tabular}{lllllll}
\hline & $\begin{array}{l}\text { The degree of } \\
\text { importance of the value } \\
\text { for the respondent }\end{array}$ & $\begin{array}{l}\text { The possibility of } \\
\text { implementing the value } \\
\text { at work }\end{array}$ & $\begin{array}{l}\text { The gap between the value's } \\
\text { importance and possibility } \\
\text { of application at work }\end{array}$ \\
\hline $\begin{array}{l}\text { Value } \\
\text { benevolence }\end{array}$ & $M$ & $S D$ & $M$ & $S D$ & $M$ & $S D$ \\
universalism & 5.39 & .67 & 5.32 & .69 & .07 & .81 \\
self-direction & 5.64 & .60 & 5.33 & .87 & .31 & .94 \\
stimulation & 5.35 & .57 & 4.51 & .96 & .84 & 1.02 \\
hedonism & 4.32 & .97 & 4.27 & .89 & .04 & 1.10 \\
achievement & 5.24 & .86 & 4.46 & 1.14 & .78 & 1.23 \\
power & 5.41 & .70 & 4.76 & .98 & .64 & 1.09 \\
security & 4.87 & 1.03 & 4.43 & 1.09 & .44 & 1.24 \\
conformity & 5.58 & .47 & 5.32 & .82 & .53 & .84 \\
tradition & 5.57 & .54 & 5.33 & .65 & .29 & .74 \\
\hline
\end{tabular}

According to Table 1, value importance varies, with universalism highest and stimulation lowest. The degree of ability to implement values also varies. The gap is not always in the same direction; that is, not every important value can be applied to a greater extent. The biggest difference is for self-direction.

Pearson's $r$ was used to check the effect of age and professional seniority on rated importance of values. Age and stimulation are significantly negatively correlated, $r=-17, p<0.001$, as are age and achievement, $r=-.16, p$ $<0.001$, and age and power, $r=-.13, p<0.001)$. In other words, the older the respondent, the less important the values. For example, professional seniority is significantly negatively correlated with stimulation, $r=-.15, p$ $<0.001$, although it is positively correlated with power, $r=.11, p<0.05$.

We also asked whether the degree of importance of values varies according to demographic, academic or professional characteristics. We found a significant difference between men and women for benevolence, $F(1,423)=11.78, p<0.001$, where women value it more highly $(M=5.46, S D=.65)$ than do men $(M=5.22, S D$ $=.70)$. Power was significantly more important to men $(M=5.04, S D=.92)$ than to women $(M=4.79, S D=$ 1.06), $F(1,423)=5.25, p<.05)$. A significant difference was found for security, $F(1,423)=6.82, p<.05)$ where women value it more highly $(M=5.62, S D=.47)$ than do men $(M=5.49, S D=.47)$.

The respondent's work role significantly affected the degree of importance of the two values hedonism, $F(4,420)$ $=2.88, p<.05)$ and achievement, $F(4,420)=2.78, p<.05)$. The degree of importance of hedonism was greatest for those in the role of team leader $(M=5.77, S D=.44)$ and the least for those in team management and supervisory positions $(M=4.75, S D=1.05)$. The importance of achievement is highest for team leaders $(M=$ $5.84, S D=.31)$ and lowest for deputy ward managers $(M=5.04, S D=1.48)$. No differences were found for place or type of department in which respondents worked.

Academic qualification significantly affected the importance of power, $F(3,411)=2.98, p<.05)$. Respondents with an M.A. or higher attributed the highest level of importance to this value $(M=5.08, S D=1.10)$ whereas its importance was lowest for registered nurses $(M=4.71, S D=1.16)$.

We also looked at the effect of demographic variables on the degree of implementation of values at work. Age had no effect, and professional seniority showed only a significant negative correlation between professional seniority and the degree of implementation of achievement, $\mathrm{r}=-0.11, p<0.05$. Differences between men and women was observed only for universalism, $F(1,423)=9.34, p<.05)$, where women $(M=5.41, S D=.80)$ reported that they could apply this value at work more than men could $(M=5.14, S D=.97)$, and the same held for conformity, $F(1,423)=4.75, \mathrm{P}<.05)$, women $(\mathrm{M}=5.30, S D=.62)$ men $(M=5.15, S D=.70)$.

The possibility of applying the values also differed by religion. Significant differences were observed for the four affiliations for the values of self-direction, stimulation, hedonism, achievement and security.

Respondent's work role affects the possibility to apply values only for power, $F(3,421)=3.22, p<.05$. The more senior and more managerial the staff member's role, the greater the ability to implement the value, as seen for regular staff $(M=4.37, S D=1.08)$, team leader $(M=4.19, S D=.80)$, deputy department head $(M=4.90, S D=$ $1.48)$, department head $(M=4.90, S D=.92)$ and team supervisor or manager $(M=5.04, S D=.91)$. 
By one-way ANOVA, we found that the department in which the staff member works affects the possibility of implementing three values: benevolence, hedonism and conformity. Working in community health clinics is conducive to implementing the values of hedonism, conformity and benevolence to a very great extent. The value of hedonism is rated as having a low possibility of implementation for the emergency and labor rooms, as it does for pediatrics.

Table 2 about here

Table 2. The effect of department on the possibility to implement three values: benevolence, hedonism and conformity $(d f=7,134)$

\begin{tabular}{lllll}
\hline Value & F & Department & $M$ & $S D$ \\
\hline Benevolence & $2.10^{*}$ & Internal medicine & 5.40 & .51 \\
& & Surgery & 5.40 & .63 \\
& & Intensive care & 5.10 & .98 \\
& & Pediatrics & 5.00 & .72 \\
& & Maternity & 5.31 & .66 \\
Hedonism & Mental health & 5.25 & .79 \\
& & Community health & 5.65 & .50 \\
& & Geriatrics & 5.36 & .48 \\
& & Internal medicine & 4.77 & .87 \\
& & Surgery & 4.73 & .70 \\
& & Intensive care & 4.20 & 1.32 \\
& & Pediatrics & 4.21 & 1.13 \\
& & Maternity & 4.00 & 1.26 \\
& & Mental health & 4.30 & .67 \\
& & Community health & 5.03 & .94 \\
& & Geriatrics & 4.71 & .95 \\
& & Internal medicine & 5.11 & .58 \\
& & Surgery & 5.55 & .46 \\
& & Intensive care & 5.17 & .91 \\
& & Pediatrics & 5.07 & .74 \\
& & Maternity & 5.51 & .57 \\
& & Mental health & 5.27 & .63 \\
& & Community health & 5.66 & .29 \\
& & Geriatrics & 5.28 & .44 \\
\hline
\end{tabular}

$* p<.05$

Table 2 shows that there are differences in the possibilities for nursing staff to implement their values in the differing clinical fields. Working in community health clinics is conducive to implementing the values of hedonism, conformity and benevolence to a very great extent. The value of hedonism is rated as having a low possibility of implementation for the emergency and labor rooms, and the same low possibility of implementing the values was noted by teams working in pediatrics.

Academic level also affects the possibility to implement values for the value of tradition, $F(3,411)=6.04, p$ $<.05$ of patients, with the lowest possibility noted by respondents with an M.A. or higher $(M=4.44, S D=1.16)$, and the highest by registered nurses $(M=5.02, S D=1.05)$.

What factors influence the gap between values held and values implemented? Age is important. A significant positive correlation was found for age and the value of benevolence; the older the respondent, the greater the gap, $r=.13, p<.001$. On the other hand, a negative correlation was found for age and stimulation, so that as age increases, the gap gets smaller, $r=-.14, p<.001$. However, professional seniority did not affect the gap.

The factor of gender influences the gap for two values only. For universalism, $F(1,423)=3.96, p<.05)$ the gap was larger for men $(M=.45, S D=1.04)$ than for women $(M=.25, S D=.88)$. Similarly, there is a difference for power, $F(1,423)=4.01, p<.05)$ where the difference for men $(M=.62, S D=1.30)$ was greater than that for women $(M=.36, S D=1.20)$.

The factors of hedonism, $F(4,420)=2.42, p<.05)$ and achievement, $F(4,420)=3.42, p<.05)$ also affect the gap. 
The biggest gap for hedonism was for a team leader $(M=1.61, S D=1.20)$, the smallest was for a team supervisor and manager $(M=.16, S D=1.30)$, and for the regular staff and deputy managers the gap was similar $(M=.70)$. The biggest gap for the value of achievement was for team leaders $(M=1.46, S D=.72)$; the smallest difference was for deputies $(M=.20, S D=1.23)$.

Respondent's academic degree showed a significant difference for hedonism, $F(3,411)=5.49, p<.05$ with the greatest difference observed among staff who held an M.A. or higher $(M=.95, S D=1.14)$, and the lowest among regular nurses $(M=.42, S D=1: 29)$.

\section{Discussion}

This study examined the personal and demographic values that characterize workers in the nursing profession, the degree to which these values can be implemented during work and the extent of the gap between them. Nursing staff noted the values of benevolence, universalism, achievement, security, and conformity as being of the highest importance, supporting. Schwartz' claim to this effect. These values contribute to the formation of good social relationships, reduce conflicts within the group, and prevent the violation of group laws and norms (Schwartz, 1992).

While achievement was rated as having high importance, Schwarz (1992) noted that despite the universality of his theory, different groups can assign varying importance to this value, thus allocating it either a positive or a disruptive effect. We too found a gap between its importance and the possibility to implement it, possibly meaning that this gap generates or is the result of negative feelings. Moreover, the gap between the value of self direction and the possibility to implement it, noted by teams that worked in different departments, suggests that teams are not given the opportunity to implement it in ways that correspond to its importance.

We also examined the influence of demographic characteristics on determining the importance and application of values, the first being age. Younger respondents rated stimulation, achievement, and power as more important than older age groups did. In addition, the age of the respondents affected the extent of the gap. We found that the older the respondent, the greater the gap for the value of benevolence, while the opposite held true for the value of stimulation. This finding supports Schwartz's theory and is similar to the findings of studies based on it. For example, differences in individual values were found by age groups in large-scale and multi-country studies such as the European Social Survey (ESS) and the World Values Survey (WVS) (Schwartz \& Rubel, 2005). The age gap for values can affect nurses' functioning and the decisions they make regarding themselves and the treatment of their patients and could lead to conflicts between caregivers of different generations.

Culture has a great influence on the development of man's perceptions and values. Value systems can differ from culture to culture, and values of individuals are influenced by the culture to which they belong (Horton, Tschudin $\&$ Forget, 2007). Teams in the various therapeutic fields are made up of individuals who bring their culture-based value systems with them, where "culture" includes the set of beliefs, values and customs that are passed on to the next generation, and shapes their decisions, perceptions, opinions, and modes of action (Wros, Dourich \& Hewison, 2001; Izumi, 2004). And although nursing professionals are part of the global community of nurses, it is still possible to see that certain professional decisions and actions are influenced by the values, customs and beliefs of the culture of the individual professional (Jiménez-López, Roales-Nieto, Seco \& Preciado, 2016). Our study found that there is a significant difference in the degree of importance of all values among teams of different cultures, and respondents from different religions reported differently on the degree to which the values could be implemented. On the other hand, religious affiliation did not affect the extent of the gap between the importance of values and the extent to which they were implemented at work. Similarly, (Rassin, 2008) found differences in approximately 12 values between groups of Israeli-born nurses compared with those who had immigrated to Israel from the Soviet Union, where the Israeli-born nurses noted the values of family security, happiness, excellence, ambition, cheerfulness, and honesty as more important than did the immigrant team.. Differences in the importance of values can lead to a lack of congruence in thinking and decision-making processes at the staff and therapeutic levels.

Academic qualifications also influence the order of the importance of personal values. Nursing staff holding an MA or higher gave the highest rating for importance to the value of power, while this variable was assigned the lowest degree of importance among RN nursing staff. In addition, the academic level of the subjects led to a significant difference in the gap between the degree of importance and the ability to implement the value of hedonism, where the largest gap was among the MA staff (and the lowest among the RNs). The impact of academic level on personal value systems has been noted before. For example, nurses with academic degrees rated the values of independence, happiness and achievement as most important, compared to licensed vocational nurses who rated family security, cleanliness, obedience, forgiveness, and politeness more highly 
(Rassin, 2008).

Staff role was also an important factor in this study. The degree of importance of the value of hedonism and achievement was highest among team leaders. Staff roles affected the possibility of implementing only one value, namely, power. The more senior and managerial the role of the staff member, the greater the ability to implement power. However, it is debatable whether the high importance of power is what motivated the teams to continue their studies and progress to the managerial level in order to obtain more power, or whether the learning process, the learned content, and the managerial role themselves led them to see power as an important value. Rassin (2008) also looked at staff level, and found that a beginning team noted happiness and ambition as more important than a senior team did. The same study found that a team without a managerial role rated politeness as more important than did a team in a managerial position. Similarly, a team in a managerial position rated the value of independence as being more important than a team without a managerial role.

Our study found that nursing staff perceive differences in the possibility to implement their values according to clinical setting. Working in community health clinics is conducive to implementing the values of hedonism, conformity and benevolence to a very great extent. This result may stem either from the fact that there are no shifts in this clinical setting, allowing for a stable work schedule, or from being located in a particular residential area or within a homogeneous culture. However, the value of hedonism is perceived as having a very low possibility of implementation for the emergency and labor wards where the patients are heterogeneous and the work is stressful.

Gender also affected the importance of the personal values of the teams. Women rated the values of benevolence and security as being more important than men did, supporting Rassin's (2008) finding. The difference between men and women was also seen for the values of universalism and conformity in the workplace, with women noting a higher degree of their implementation. Universalism among men had a greater disparity in rating than among women, and variance was also found in the power value gap, where the gap for men was greater than that for women.

\section{Conclusions and Recommendations}

Personal value systems determine behavior and influence decision-making processes Values with high importance may not necessarily be implementable in the workplace, and this is reflected in the gap between the degree of importance and the degree of implementation, a difference that varies by clinical field. Demographic and professional characteristics influence the perceived degree of the values' importance, the degree to which the value is implementable, and the gap between them. Age, cultural affiliation, gender, level of academic studies, degree and job definition may all affect perceptions. Understanding this variability can be important for making the right decisions about teamwork such as consensus solving, promotion decisions, and role assignment.

Since the individual's value system influences the behavior and decision-making process of a team, an examination of the personal values of applicants for nursing studies and an examination of their suitability for the profession can contribute to the selection of the most appropriate candidates. However, we would like to note the clear limitation that our respondents were mostly from one geographical area, which may have introduced bias into the results.

\section{Application}

Knowledge of the dominant personal values held by nursing staff may contribute to the organization's ability to cultivate and maintain the human resources within it. Institutions should be aware of possible gaps between the importance of values and the degree of their implementation and that there might be negative effects of the gaps, and should strive to reduce them.

\section{References}

Bardi, A., \& Schwartz S.H. (2003). Values and behavior: Strength and structure of relations. Personality and Social Psychology Bulletin, 29(10), 1207-1220. https://doi.org/10.1177/0146167203254602

Dolan, S.L. (2011). Coaching by Values: A Guide to Success in the Life of Business and the business of Life. iUniverse, Bloomington, IN.

Hewison, A. (2001). Values in the National Health Service: implication for nurse managers. Journal of Nursing Management, 9, 253-258. https://doi.org/10.1046/j.1365-2834.2001.00251.x

Horton, K., Tschudin, V., \& Forget, A. (2007). The value of nursing: A Literature review. Nursing Ethics, 14(6), 176-740. https://doi.org/10.1177/0969733007082112

Jiménez-López, F., Roales-Nieto, J., Seco, G., \& Preciado, J. (2016). Values in nursing students and 
professionals: An exploratory comparative study. Nursing Ethics, 23(1), 79-97. https://doi.org/10.1177/0969733014557135

Maben, J., Latter, S., \& Clark, J.M. (2007). The sustainability of ideals, values and nursing mandate: Evidence from a longitudinal qualitative study. Nursing Inquiry, 14, 99-113. https://doi.org/10.1111/j.1440-1800.2007.00357.x

Rassin, M. (2008). Nurses' professional and personal values. Nursing Ethics, 15, 614-630. https://doi.org/10.1177/0969733008092870

Sagiv, L., \& Schwartz, S. (2000). Value priorities and subjective wellbeing: Direct relations and congruity effects. $\begin{array}{llllll}\text { European Journal } & \text { of } & \text { Social } & \text { Psychology, } & 30, & 177-198 .\end{array}$ https://doi.org/10.1002/(SICI)1099-0992(200003/04)30:2<177::AID-EJSP982>3.0.CO;2-Z

Schwartz, S.H. (1992). Universals in the content and structure of values: Theory and empirical tests in 20 countries. In M. Zanna (Ed.), Advances in Experimental Social Psychology (Vol. 25, pp. 1-65). New York: Academic Press. https://doi.org/10.1016/S0065-2601(08)60281-6

Schwartz, S.H. (2003). A proposal for measuring value orientations across nations (Chapter 7). In Questionnaire development package of the European Social Survey. Retrieved from http://ess.nsd.uib.no/ess

Schwartz, S.H. (2006). Value orientations: Measurement, antecedents and consequences across nations. In Jowell, R., Roberts, C., Fitzgerald, R., \& Eva, G. (Eds.), Measuring attitudes cross-nationally-lessons from the European Social Survey (pp.169-203). London, UK: Sage.

Schwartz, S.H. (2011). Values: Individual and cultural. In Van de Vijver, F.J.R., Chasiotis, A., \& Breugelmans, S.M. (Eds.), Fundamental Questions in Cross-Cultural Psychology. Cambridge, UK: Cambridge University Press.

Schwartz, S.H. (2012). An overview of the Schwartz theory of basic values. Online Readings in Psychology and Culture, 2(1). https://doi.org/10.9707/2307-0919.1116

Schwartz, S.H., \& Bardi, A. (2001). Value hierarchies across cultures: Taking a similarities perspective. Journal of Cross-Cultural Psychology, 32, 268-290. https://doi.org/10.1177/0022022101032003002

Schwartz, S.H., \& Rubel, T. (2005). Sex differences in value priorities: Cross-cultural and multimethod studies. Journal of Personality and Social Psychology, 89, 1010-1028. https://doi.org/10.1037/0022-3514.89.6.1010

The ICN Code of Ethics for Nurses. (2012). International Council of Nursing.

World Health Organization (WHO). (2006). Working Together for Health: The World Health Report. Geneva: WHO.

Wros, P.L., Doutrich, D., \& Izumi, S. (2004). Ethical concerns: Comparison of values of two cultures. Nursing Health Science, 6, 131-140. https://doi.org/10.1111/j.1442-2018.2004.00184.x

\section{Copyrights}

Copyright for this article is retained by the author(s), with first publication rights granted to the journal.

This is an open-access article distributed under the terms and conditions of the Creative Commons Attribution license (http://creativecommons.org/licenses/by/4.0/). 